\title{
Auditory Brainstem Response Audiometry in Congenitally Hypothyroid Children Under Early Replacement Therapy
}

\author{
RÉAL HÉBERT, EMMANUELE LAUREAU, MICHEL VANASSE, JOSEPH-EDOUARD RICHARD, \\ JEAN MORISSETTE, JACQUELINE GLORIEUX, MANON DESJARDINS, JACQUES LETARTE, \\ AND JEAN H. DUSSAULT \\ Centre Hospitalier de l'Université Laval, Sainte-Foy [R.H., J-E.R., J.M., J.H.D.]; Hôpital Sainte-Justine, \\ Montréal [E.L., M.V., J.G., M.D., J.L.]; and Le Réseau de Médecine Génétique du Québec, [J.M., J.G., M.D., \\ J.L., J.H.D.J, Québec, Canada
}

\begin{abstract}
Using auditory brainstem response audiometry, we evaluated 34 congenital hypothyroidism children under thyroid hormone therapy and 24 age- and sexmatched controls between 5 and 12 yr of age. Two main auditory brainstem response abnormalities were encountered: first, prolonged wave I latencies, secondary to a peripheral impairment, were found in seven congenital hypothyroidism children $(20 \%)$ : three of these showed signs of serious otitis media, unilaterally in two and bilaterally in the other, at the time of the evaluation. Second, shortened I-V interpeak latencies were observed in $\mathbf{1 0}$ children $(29 \%)$. No correlation was found between the interpeak latencies and the $L$-thyroxine serum values at the time of the test or just prior to treatment initiation. Also, there was no correlation with estimated bone age at treatment initiation or with the Griffiths global mental development quotients assessed at $5 \mathrm{yr}$ of age. These preliminary results suggest a significant incidence of auditory brainstem response abnormalities in treated hypothyroid children. (Pediatr Res 20: 570-573, 1986)
\end{abstract}

\section{Abbreviations}

ABR, auditory brainstem response

$\mathrm{CH}$, congenital hypothyroidism

$T_{4}$, L-thyroxine

IPL, interpeak latency

The mental prognosis of infants with $\mathrm{CH}$ is improved when treatment is initiated before 3 months of age $(1,2)$. Since the development of newborn hypothyroid screening, treatment usually is initiated before 2 months of age. Earlier data have suggested that even early treated children may manifest neuropsychological dysfunction which may handicap development $(3,4)$. Glorieux et al. (5), studying a group of 3-yr-old early treated $\mathrm{CH}$ children, observed a significant positive correlation between the individual Griffiths global quotients (Griffiths developmental test) (6) and either the serum $T_{4}$ levels or bone age estimated just prior to treatment initiation. Furthermore, as early as 18 months of age, these children had lower scores in the hearing-speech Griffiths scale than a control group (7). In addition, there is a

Received November 25, 1985; accepted February 11, 1986.

The study was supported by the Fonds de la Recherche en Sante du Québec.

Correspondence and reprint requests Jean H. Dussault, M.D., M.SC. F.R.C.P.(C), Laboratoires de Recherches en Endocrinologie et Métabolisme C.H.U.L., 2705 Boul. Laurier, Sainte-Foy, Québec, G1V 4G2, Canada well-known association between hearing loss and hypothyroidism (8-12). ABR audiometry has proven to be reliable for the assessment of the peripheral auditory function in very young children and for the follow-up of the central auditory pathway maturation (13-18). In the case of a child diagnosed as hypothyroid at 2 yr of age, Mendel and Robinson (19) reported that $A B R$ audiometry results, together with speech and growth, were markedly improved after $T_{4}$ replacement therapy had been initiated.

In the present study, we used the $\mathrm{ABR}$ audiometry in $\mathrm{CH}$ children for two purposes: first, to look for an association between psychological and eventual electrophysiological abnormalities in $\mathrm{CH}$ children as an early indicator of infants at particular risk and, second, for the early detection of eventual hearing problems. Data obtained in the group of treated $\mathrm{CH}$ children between 5 and $12 \mathrm{yr}$ old suggest a significant prevalence of $\mathrm{ABR}$ abnormalities.

\section{MATERIALS AND METHODS}

The subjects were 58 children aged 5 to 12 yr: 34 were diagnosed $\mathrm{CH}$ by neonatal thyroid screening (20) during the first weeks of life and promptly treated with $\mathrm{T}_{4}$ (Synthroid, Flint Laboratory of Canada). Twenty-four children were normal controls matched for age and sex. The $\mathrm{CH}$ children were maintained under close biochemical, developmental, and psychological follow-up by two university-affiliated hospitals. Each child received a routine otological examination before the ABR evaluation. The test was performed after informed consent of the parents. Any control children with otitis media or a significant history of ear infections were excluded from the study.

Instrumentation and procedures. The acoustic stimulus consisted of clicks delivered monaurally through cushioned earphones. Square wave pulses of alternated polarity (duration: 0.1 $\mathrm{ms}$ ) were generated by digital stimulators (NICOLET or TECA ST-10) at the rate of $10 / \mathrm{s}$. The click intensity was calibrated in $\mathrm{dB}$ HL (hearing level) with reference to thresholds obtained from a normal group of adults.

The electrical activity was picked up with EEG surface electrodes. The positive $(+)$ was located prefrontally at FPZ (10-20 System) and the negative (-) on the mastoid ipsilateral to the ear currently stimulated. Subject grounding was provided by a contralateral mastoid electrode placement. Electrode impedance was kept less than $5 \mathrm{kOhm}$. The EEG activity was filtered (NICOLET: $150-3000 \mathrm{~Hz}$ or TECA: $200-2000 \mathrm{~Hz}$ ), amplified ( $\times$ $10^{5}$ ) and averaged $0.04 \mathrm{~ms}$ resolution). The different filter settings, due to equipment variation, were verified to have no effect on ABR peak latencies. The responses to 1000 clicks were 
recorded and two traces were superimposed in order to check for peak replicability. Both ears were evaluated for each child. The tests were conducted on nonsedated children, usually awake. The peak latencies of waves I and V (21) and the corresponding IPL were calculated. There is recent evidence that wave $\mathrm{V}$ is generated in the lateral lemniscus region in man (22). Since there is some controversy about the wave (II or III) which reflects the activation of the first auditory brainstem relay (23), we considered this I-V IPL as a central conduction time even though it includes an auditory nerve conduction time component. Normal threshold was assumed when there was a replicable wave $\mathrm{V}$ at $20 \mathrm{~dB}$ HL. The I-V IPL values were correlated with the results of a mental development evaluation performed at $5 \mathrm{yr}$ of age in these $\mathrm{CH}$ children (24) using the Griffiths test.

Serum $\mathrm{T}_{4}$, triiodothyronine, and thyrotropin were usually determined the same week of the ABR evaluation. Results are expressed as the mean $\pm 2 \mathrm{SD}$. Intergroup comparisons were made with the two-tailed Student's $t$ test.

\section{RESULTS}

The otological examination of the hypothyroid children revealed signs of serous otitis media in four. One, affected bilaterally, was evaluated when cured and the others (two with unilateral and 1 with bilateral signs of serous otitis media) were tested immediately, largely because they lived a long distance from the hospital. In the control group, no statistically significant differences were evident between the male and female subgroups for the different ABR parameters, even though the I-V IPLs tended to be shorter in female subjects (Table 1 ). In view of the conclusive evidence from the literature for a sex difference (25), we considered it worthwhile to have separate ABR norms for males and females.

The female group of hypothyroid children had significantly shorter mean wave V latency and I-V IPLs compared to the controls (Table 1). Eight (36\%) (Table 2) showed abnormally short wave $\mathrm{V}$ latencies and I-V IPLs $(<$ mean $-2 \mathrm{SD})$. Of these, five had short I-V IPLs bilaterally. In four female children (18\%), wave I latencies were increased ( $>$ mean $+2 \mathrm{SD})$, bilaterally in three. In one of these, which showed signs of unilateral serous otitis media, the increase in latency was limited to the affected side. No significant differences $(p>0.05)$ were evident between the male hypothyroid children and their control counterparts for the mean values of $\mathrm{ABR}$ parameters (Table 1). However, three male $\mathrm{CH}$ children $(25 \%)$ (Table 2 ) showed prolonged wave I latencies. Of these, two showed signs of serous otitis media (unilaterally in one and bilaterally in the other) and displayed prolonged wave I latencies on the affected ears recordings. One child displayed a unilaterally prolonged I-V IPL and a upper limit value for the other side. In two others, there were bilaterally shortened wave V latencies and I-V IPLs. On the 10 children (two males and eight females) with shortened I-V IPLs, only one showed prolonged latencies for wave I. The other nine children $(26 \%)$ displayed normal wave I latencies.

Figure 1 displays typical ABR replicated traces obtained with

Table 1. Peak $(I, V)$ and interpeak $(I-V)$ latencies in control and $\mathrm{CH}$ of children tested (both ears were evaluated)

\begin{tabular}{|c|c|c|c|c|}
\hline & \multirow[b]{2}{*}{ Ears } & \multicolumn{3}{|c|}{$\begin{array}{c}\text { Latency (ms) } \\
(\text { mean } \pm 2 S D)\end{array}$} \\
\hline & & $\mathrm{I}$ & $\mathrm{V}$ & $\mathrm{I}-\mathrm{V}$ \\
\hline \multicolumn{5}{|l|}{ Male group } \\
\hline Control & 22 & $1.44( \pm 0.16)$ & $5.43( \pm 0.20)$ & $4.00( \pm 0.24)$ \\
\hline Hypothyroid & 24 & $1.48( \pm 0.32)$ & $5.49( \pm 0.50)$ & $4.01( \pm 0.40)$ \\
\hline \multicolumn{5}{|l|}{ Female group } \\
\hline Control & 26 & $1.46( \pm 0.20)$ & $5.40( \pm 0.20)$ & $3.94( \pm 0.24)$ \\
\hline Hypothyroid & 44 & $1.51( \pm 0.26)$ & $\begin{array}{c}5.29( \pm 0.44) \\
(p<0.05)\end{array}$ & $\begin{array}{c}3.77( \pm 0.32) \\
(p<0.001)\end{array}$ \\
\hline
\end{tabular}

Table 2. ABR abnormalities in $\mathrm{CH}$ children

\begin{tabular}{cccc}
\hline & $\mathrm{I}$ & $\mathrm{V}$ & $\mathrm{I}-\mathrm{V}$ \\
\hline Lengthened latencies & & & \\
Male $(n=12)$ & 3 & 4 & 2 \\
Female $(n=22)$ & 4 & 3 & 0 \\
& & & \\
Shortened latencies & & & \\
Male $(n=12)$ & 0 & 2 & 2 \\
Female $(n=22)$ & 0 & 8 & 8 \\
\hline
\end{tabular}

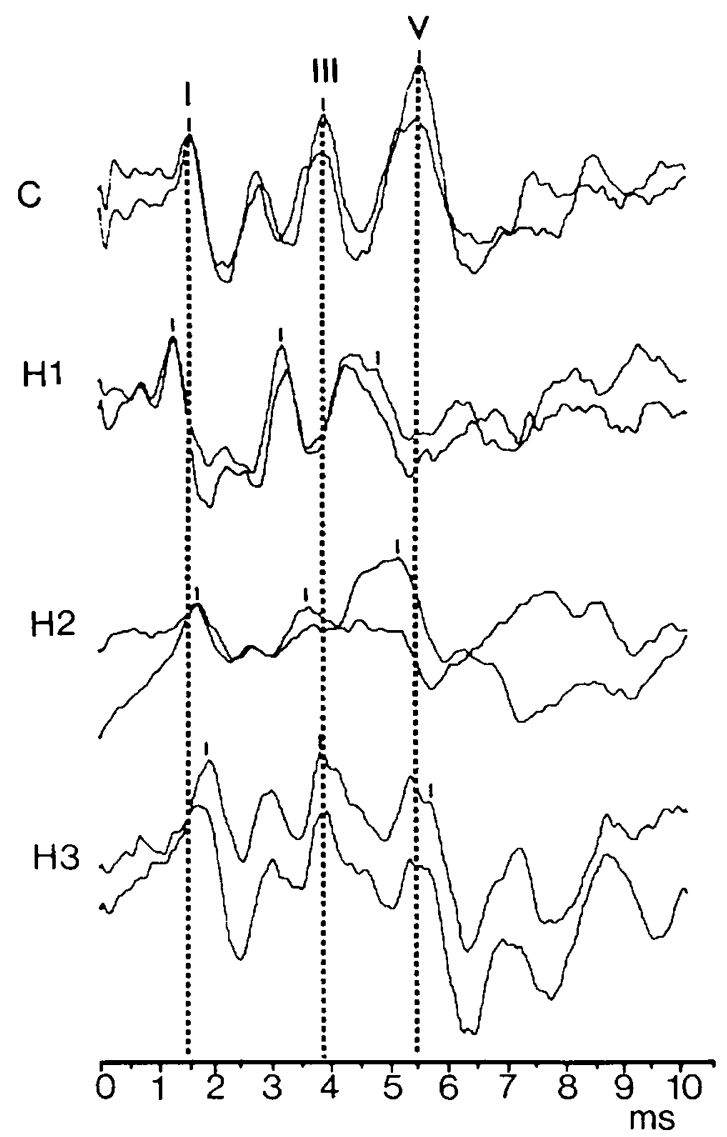

Fig. 1. Control $(C)$ and $\mathrm{CH}$ children $(H 1, H 2, H 3) \mathrm{ABR}$ traces. The traces at the top $(C)$ are from a control child and waves I, III, and V are indicated. The traces identified as $\mathrm{H} 1, \mathrm{H} 2$, and $\mathrm{H} 3$ are from three $\mathrm{CH}$ children with abnormalities. In $\mathrm{H} 1$, both wave $\mathrm{V}$ latency and I-V IPL are shortened (< mean $-2 \mathrm{SD})$. Wave I latency, although shorter than the controls, is in the normal range. In $\mathrm{H} 2$, wave I latency is normal and wave $\mathrm{V}$ latency is at the inferior limit of normality. The traces at the bottom $(\mathrm{H} 3)$ show lengthened wave I and $\mathrm{V}$ latencies with a normal I-V IPL. The intensity of stimulation was $75 \mathrm{~dB}$ hearing level.

$75 \mathrm{~dB}$ hearing level stimulation. The first ones were obtained from a control subject $(\mathrm{C})$ and the others $(\mathrm{H} 1, \mathrm{H} 2, \mathrm{H} 3)$ from hypothyroid children showing typical abnormalities. Figure 2 compares the individual peak latencies (waves $I$ and $V$ ) in the two experimental groups. Figure 2 illustrates some wave I latency increases and abnormally short wave $\mathrm{V}$ latencies in the hypothyroid children (males and females). Figure 3 shows the individual I-V IPLs, stressing the abnormally short values often observed.

The mean $\pm 1 \mathrm{SD} \mathrm{T}_{4}$ serum levels at the time of the ABR test were $13.6 \pm 3.1$ and $13.7 \pm 3.3 \mu \mathrm{g} / 100 \mathrm{ml}$ for male and female children, respectively (normal: $5-14 \mu \mathrm{g} / 100 \mathrm{ml}$ ). No correlation was found between these $\mathrm{T}_{4}$ serum levels and the wave I $(r=$ $0.02)$ or the I-V IPL $(r=0.09)$ values in the hypothyroid children. No significant correlation was found between those I-V IPL values and the $\mathrm{T}_{4}(r=0.01)$ or the bone age (knee area as 


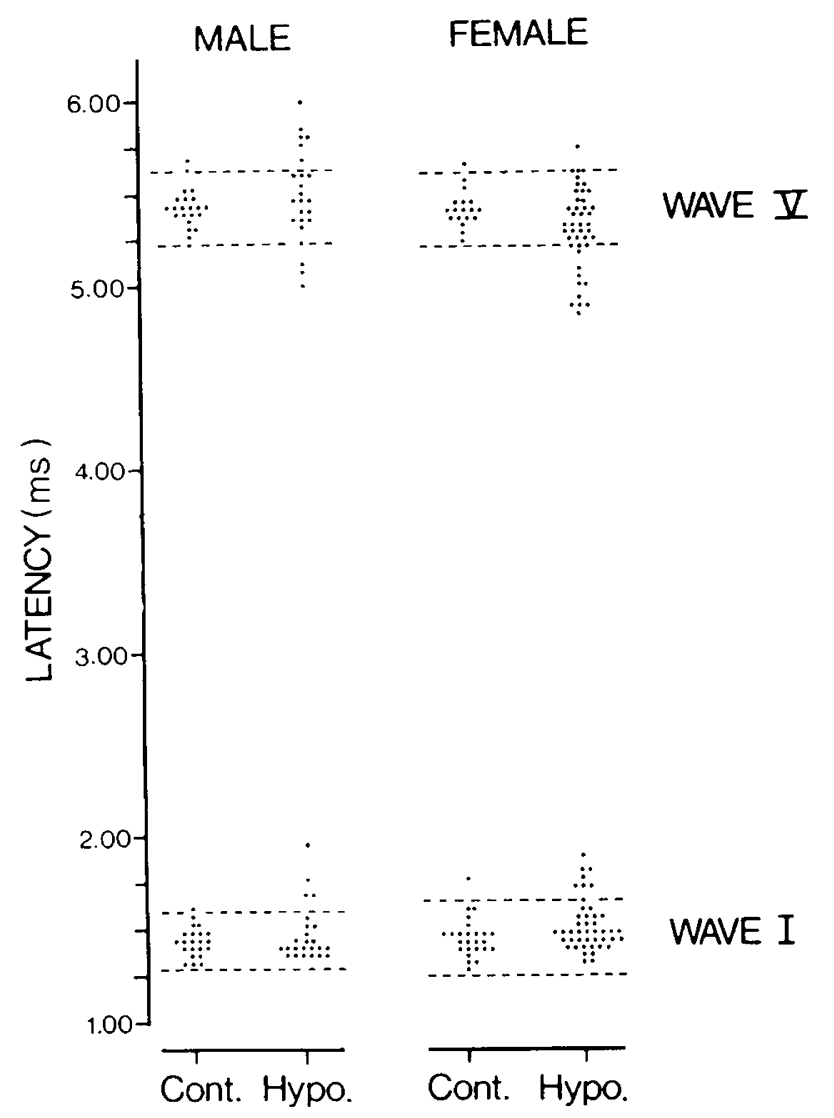

Fig. 2. Peak latencies of waves I and V in the control and hypothyroid groups of children. The dotted lines represent $\pm 2 \mathrm{SD}$ around the control mean. Since both ears were evaluated, there are two values for each child. The first main abnormality consists of prolonged wave I latencies in some of the male and female $\mathrm{CH}$ children. Secondly, wave $\mathrm{V}$ latency was lengthened in some cases or, more often, shortened in an important proportion of the $\mathrm{CH}$ children. The intensity of stimulation was $75 \mathrm{~dB}$ HL.

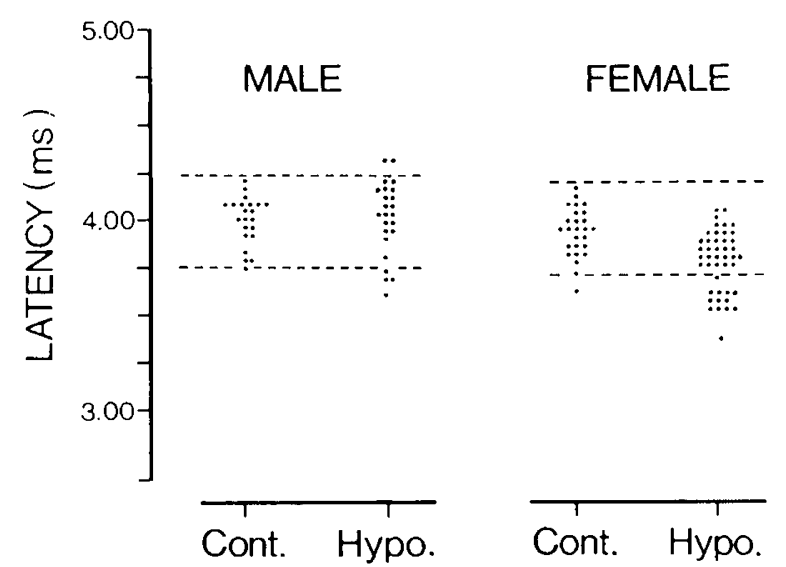

Fig. 3. I-V interpeak latencies obtained in the control and hypothyroid groups of children. The dotted lines represent $\pm 2 \mathrm{SD}$ around the control mean. The main abnormality consists in shortened intervals.

described in Reference 26) ( $r=0.41)$ values at the time of treatment initiation, or with the Griffiths global development quotient $(r=0.02)$ or the hearing-speech scale values $(r=0.01)$.

\section{DISCUSSION}

The present results show that $\mathrm{ABR}$ abnormalities are found in some early treated $\mathrm{CH}$ children. Two main types of electrophys- iological abnormalities were observed: first, there was an increase of wave I latency in seven children. This peak reflects the activation of the peripheral auditory apparatus, and an increase of its latency is usually secondary to a peripheral impairment, conductive and/or sensorineural in nature (27-29). Second, a shortening of the I-V IPL without wave I latency increase characterized the ABR traces of nine other children.

The first type of ABR abnormalities, characteristic of a peripheral hearing loss, is reminiscent of the audiometric findings of Vanderschueren-Lodeweyckx et al. (12); these authors described various degrees of sensorineural hearing loss in $20 \%$ of treated hypothyroid children. Although this figure is identical to the percentage of children with prolonged wave I latencies in the present study, three of these children showed signs of serous otitis media which might have caused a temporary hearing loss and affected wave I. The proportion of $\mathrm{CH}$ children with signs of middle ear infection in the present group (11\%) does not differ from that reported in 4-yr-old children $(10-18 \%)$ by Tos et al. (30). Even though we did not utilize pure-tone audiometry to document the extent of the hearing loss or middle ear function tests (e.g. tympanometry) to uncover the site of the alteration, our data are in agreement with earlier work of others who suggested a higher occurrence of hearing problems in a $\mathrm{CH}$ population than in control children (12). Moreover, and also in agreement with these authors (12), we could not establish any relationship between hearing acuity and chronological or bone age at diagnosis of $\mathrm{CH}$. From recent studies $(5,26)$, neonatal bone age estimation has been shown to be a good index of the severity of hypothyroidism.

The second major type of ABR abnormalities encountered was a shortening of I-V IPLs without a wave I latency increase. Himelfarb et al. (31), also using ABR, described a good correlation between brainstem conduction time and the level of serum $\mathrm{T}_{4}$ in acquired hypo- and hyperthyroidism. Hypothyroid patients tended to have prolonged brainstem conduction times whilst hyperthyroid subjects displayed shortened times. In our study, although 15 treated $\mathrm{CH}$ children (44\%) exhibited high serum $\mathrm{T}_{4}$ levels $(>14 \mu \mathrm{g} / \mathrm{dl})$ with correspondingly low TSH values, we were unable to establish a significant correlation between these hormone levels and the I-V IPLs. On the other hand, Coats and Martin (28) reported decreased I-V IPLs with increased wave I latencies in subjects with steeply sloping audiograms in the high frequency region. This could be related to a recruitment phenomenon as observed in cochlear hearing loss, and would be associated with elevated ABR thresholds (29). In our study, only one $\mathrm{CH}$ child showed bilaterally prolonged wave I, shortened I-V IPLs and elevated thresholds; the others with shortened I-V IPLs had both normal wave I latencies and thresholds (reproducible wave $\mathrm{V}$ at $20 \mathrm{~dB}$ ). A cochlear alteration could account for these observations. The short I-V IPLs without wave I prolongation also have been observed in Down's syndrome adults $(32,33)$. Unfortunately, no puretone audiograms were performed. The authors pointed out that these ABR abnormalities were independent of the rate of the stimulation or of electrode placement, and they observed no correlation between the I-V IPLs and the IQs. In the present study, we observed no correlation between the I-V IPLs and the Griffiths global mental development quotients or the hearing-speech scores.

These preliminary results suggest that hearing acuity should be systematically assessed in CH children. At this time, there is no correlation between the $\mathrm{ABR}$ results and the psychological data in these 5-12 yr old children and definitive conclusions must await the evaluation of younger children.

\section{REFERENCES}

1. Raiti S, Newns GH 1971 Cretinism: early diagnosis and its relation to mental prognosis. Arch Dis Child 46:692

2. Klein AH, Meltzer S, Kenny FM 1972 Improved prognosis in congenital hypothyroidism treated before age 3 months. J Pediatr 81:912-915

3. MacFaul R, Dorner S, Brett EM, Grant DB 1978 Neurological abnormalities 
in patients treated for hypothyroidism from early life. Arch Dis Child 53:611619

4. Wolter R, Noel P, De Cock P, Craen M, Ernould C, Malvaux P, Verstraeten F Simons J, Mertens S, Vanbroeck N, Vanderschueren-Lodeweyckx M 1979 Neuropsychological study in treated thyroid dysgenesis. Acta Paediatr Scand [Suppl] 277:41-46

5. Glorieux J, Dussault JH, Letarte J, Guyda H, Morissette J 1983 Preliminary results on the mental development of hypothyroid infants detected by the Quebec Screening Program. J Pediatr 102:19-22

6. Griffiths R 1954 The Abilities of Babies. University of London Press, London

7. Dussault JH, Letarte J, Glorieux J, Morissette J and Guyda H 1980 Psychological development of hypothyroid children of age 12 and 18 months. Experience after neonatal screening. In: Burrow GN (ed) Neonatal Thyroid Screening. Raven Press, New York, pp 271-276

8. Rubenstein M, Rubenstein C. Theodor R 1974 Hearing dysfunction associated with congenital sporadic hypothyroidism. Ann Otol Rhinol Laryngol 83:814-819

9. Meyerhoff WL 1975 The thyroid and audition. Laryngoscope 85:483-489

10. Meyerhoff WL 1979 Hypothyroidism and the ear: electrophysiological, morphological and chemical considerations. Laryngoscope 89:1-25

11. Crifò S, Lazzari R, Salabé GB, Gagliardi M, Maragoni F 1980 A retrospective study of audiological function in a group of congenital hypothyroid patients. Int J Pediatr Otorhinolaryngol 2:347-355

12. Vandershueren-Lodeweyckx M, Debruyne F, Dooms L, Eggermont E, Eeckels R 1983 Sensorineural hearing loss in sporadic congenital hypothyroidism. Arch Dis Child 58:419-422

13. Hecox K, Galambos R 1974 Brain stem auditory evoked responses in human infants and adults. Arch Otolaryngol 99:30-33

14. Mokotoff B, Schulman-Galambos C, Galambos R 1977 Brainstem auditory evoked responses in children. Arch Otolaryngol 103:38-43

15. Schulman-Galambos C, Galambos R 1979 Brain stem evoked response audiometry in newborn hearing screening. Arch Otolaryngol 105:86-90

16. Starr A, Amlie R, Martin WH, Sanders S 1977 Development of auditory function in newborn infants revealed by auditory brainstem potentials. Pediatrics 60:831-839

17. Bernard PA, Péchère JC, Hébert R 1980 Altered objective audiometry in aminoglycoside-treated human neonates. Arch Otorhinolaryngol 228:205210

18. Robier A, Lemaire MC, Garreau B, Ployet MJ, Martineau J, Delvert JC, Reynaud J 1983 Auditory brain stem responses and cortical auditory-evoked potentials in difficult-to-test children. Audiology 22:219-228

19. Mendel D, Robinson M 1978 Electrocochleography in congenital hypothy- roidism. Dev Med Child Neurol 20:664-667

20. Dussault JH 1983 History and impact of screening programs for congenital hypothyroidism. In Dussault JH, Walker P (eds) Congenital Hypothyroidism. Marcel Dekker Inc., New York, pp 163-167

21. Jewett DL, Romano MN, Williston JS 1970 Human auditory evoked potentials: possible brain stem components detected on the scalp. Science 167:1517-1518

22. Moller AR, Jannetta PJ 1982 Evoked potentials from the inferior colliculus in man. Electroencephalogr Clin Neurophysiol 53:612-620

23. Moller AR, Jannetta PJ, Moller MB 1981 Neural generators of brainstem evoked potentials. Results from human intracranial recordings. Ann Otol Rhinol Laryngol 90:591-596

24. Dussault JH, Morissette J, Glorieux J, Desjardins M, Letarte J, Guyda H Follow-up at age 5 and 7 on the mental development of hypothyroid children detected by the Quebec Screening Program (in press)

25. Mochizuki Y, Go T, Ohkubo H, Motomura T 1983 Development of human auditory evoked potentials and gender differences from infants to young adults. Prog Neurobiol 20:273-285

26. Letarte J, Guyda H, Dussault JH 1980 Biochemical and radiological features of neonatal hypothyroid patients. In: Burrow GN, Dussault JH (eds) Neonatal Thyroid Screening. Raven Press, New York, pp 225-236

27. Stockard JJ, Rossiter VS 1977 Clinical and pathologic correlates of brain stem auditory response abnormalities. Neurology 27:316-325

28. Coats A, Martin J 1977 Human auditory nerve action potentials and brainstem evoked responses: effects of audiogram shape and lesion location. Arch Otolaryngol 103:605-623

29. Rosenhamer HJ, Lindstrom B, Lundborg T 1981 On the use of click-evoked electric brainstem responses in audiological diagnosis. III. Latencies in cochlear hearing loss. Scand Audiol 10:3-11

30. Tos M, Holm-Jensen S, Hjort Sorensen C, Mogensen C 1982 Spontaneous course and frequency of secretory otitis in 4-year-old children. Arch Otolaryngol 108:4-10

31. Himelfarb MZ, Lakretz T, Gold S, Shanon E 1981 Auditory brain stem responses in thyroid dysfunction. J Laryngol Otol 95:679-686

32. Squires N, Aine C, Buchwald J, Norman R, Galbraith G 1980 Brain stem response abnormalities in severely and profoundly retarded adults. Electroencephalogr Clin Neurophysiol 50:172-185

33. Squires N, Buchwald J, Liley F, Strecker J 1982 Brainstem auditory evoked potential abnormalities in retarded adults. In: Courjon $J$, Mauguière F, Revo M (eds) Clinical Applications of Evoked Potentials in Neurology. Raven Press, New York, pp 233-240 